\title{
NEUROLOGICAL EVALUATION OF NEONATES WITH INTRAVENTRICULAR AND PERIVENTRICULAR HEMORRHAGE
}

\author{
MONICA SANCHEZ-STOPIGLIA*, M. VALERIANA L. MOURA-RIBEIRO**, SÉRGIO MARBA***
}

\begin{abstract}
We studied the clinical aspects of 100 consecutive premature newborns with and without intraventricular and periventricular hemorrhage (IPVH). The diagnosis of IPVH was obtained by ultrasonic scans of the skull during the first week of life and at the age of one month. Forty eight percent of newborns with IPVH had abnormal results, and there was a significant correlation with the neurological evaluation in $85 \%$ of the infants. The probability of normality for a child with no associated brain abnormalities was $72 \%$, whereas for a child of the same gestational age with associated brain abnormalities was $48.7 \%$.
\end{abstract}

KEY WORDS: intraventricular and periventricular hemorrhage, neonate, premature newborn, cranial ultrasound.

\section{Avaliação neurológica de recém-nascidos com hemorragia intraventricular e periventricular}

RESUMO - Foram estudados os aspectos clínicos de 100 recém-nascidos prematuros, com e sem hemorragia periventricular-intraventricular (HPIV). O diagnóstico foi obtido através de exames ultra-sonográficos de crânio, realizados durante a primeira semana de vida e na idade corrigida de um mês.Quarenta e oito por cento dos recém-nascidos com HPVI evidenciaram resultados anormais, sendo a correlação significativa com a evolução neurológica, em $85 \%$ das crianças. Crianças que não apresentaram anormalidades cerebrais associadas tiveram $72 \%$ de probabilidade de manter a evolução normal, enquanto para crianças da mesma idade gestacional porém com anormalidades cerebrais associadas, a probabilidade foi $48,7 \%$.

PALAVRAS-CHAVE :hemorragia intraventricular e periventricular, recém-nascido, prematuro, ultrasom craniano.

In recent years, diligent perinatal assistance has improved the survival of preterm neonates with intraventricular and periventricular hemorrhage. In premature newborns, this pathological condition may result in structural changes during brain development, and may influence speech acquirement, visual motility integration, behavior, and learning at school ${ }^{1}$

The aim of this study was to evaluate, through neurological examination and ultrasonic scans, premature newborns with and without intraventricular and periventricular hemorrhage (IPVH).

Disciplina de Neurologia Infantil do Departamento de Neurologia da Faculdade de Ciências Médicas, Universidade Estadual de Campinas (UNICAMP): *Mestre, Fisioterapeuta do CAISM - UNICAMP, **Professor Associado da Disciplina de Neurologia Infantil da Faculdade de Ciências Médicas (FCM), UNICAMP; ***Professor Doutor da Área de Neonatologia do Departamento de Pediatria da FCM UNICAMP. Aceite: 11-março-1999.

Dra. M.Valeriana L. de Moura Ribeiro - Departamento de Neurologia FCM - UNICAMP - Caixa Postal 6111 13083-970 Campinas SP - Brasil. 


\section{METHOD}

A comparative study was carried out in a population of preterm neonates with IPVH ( 50 patients ) and without IPVH ( 50 controls), based on the following variables: IPVH levels, gestational age, weight, Apgar score, use of assisted ventilation, frequency of abnormal neurological signs, and associated brain abnormalities (periventricular leukomalacia, porencephalic cysts, ventricular dilatation, ventricular peritoneal deviation and brain atrophy). All the children have been evaluated at the Neonatology Service-CAISM, UNICAMP,Campinas, SP, Brazil, from August 1992 to October 1994.

This study consisted of 100 premature neonates with birth weights in grams grouped between 500-750; 751-1000; 1001-1250; 1251-1500;-1501-1750, and gestational age in weeks between 27-29; 30-32; 33-35; 3638; studied with a corrected age of 40 weeks.

The diagnosis of IPVH was obtained by ultrasonography of the skull carried out during the first week of life and at the age of one month. The test was done by a qualified professional in the Neonatology Service at CAISM using a Sonnel 300 (CGR) equipment in real time with sectorial transducter of $5 \mathrm{MHz}$. Infants with malformations or unfavorable clinical conditions were excluded from the study.

The IPVH classification used was based on the modified criteria of Papile ${ }^{2}$. The neonates were evaluated at 40 weeks of age corrected according to neurological tests proposed by Dubowitz et al., ${ }^{3,4}$. The state of consciousness at the time of evaluation was recorded using the six levels suggested by Brazelton ${ }^{5}$.

The evaluations were carried out between nursings and were classified as: Normal, normal tonus for gestational age and no more than one abnormal sign; Abnormal, three abnormal signs, trunk hypotonia and fallen head; and Suspected, two abnormal signs and incomplete head control. Initially, univariate analyses were done to examine the behavior of the independent variables relative to dependent ones. A final model was created using the variables with $p$ values less than 0.05 for the multivariate polytomic logistic regression ${ }^{5,6}$.

\section{RESULTS}

The neurological evaluation showed normal results for most of the neonates without IPVH. In contrast $48 \%$ of the neonates with IPVH had abnormal or suspicious results (Table 1).There was a significant relationship between the most serious IPVH levels (III and IV) and the occurrence of abnormal and suspicious neurological evaluations (Table 2).

The most frequent abnormal neurological signs in newborns with IPVH were: trunk hypotonia and fallen head, abnormal flexor tonus in the upper and lower limbs, abnormal head control, persistent adduction of the thumb, poor orientation, asymmetry and increase of tremor and startles.In the newborns without IPVH, the signs were: abnormal head control, trunk hypotonia and fallen head (Table 3).

The brain abnormalities associated with IPVH ( periventricular leukomalacia, porencephalic cysts, ventricular dilatation, ventricular-peritoneal derivation and brain atrophy) showed a significant correlation with the neurological evaluation in $85 \%$ of the children (Table 4). For statistical analysis, the newborns were grouped in age ranges of 27-31 weeks and $32-35$ weeks.

Table 1. Neurological evaluation of newborns with and without IPVH

\begin{tabular}{lcc}
\hline Neurological evaluation & \multicolumn{2}{c}{ IPVH } \\
\cline { 2 - 3 } & Absent & Present \\
\hline Normal & 35 & 26 \\
Abnormal & 5 & 12 \\
Suspicious & 10 & 12 \\
Total & 50 & 50 \\
\hline
\end{tabular}

Table 2. Neurological evaluation of newborns according to the levels of IPVH.

\begin{tabular}{lcccc}
\hline Neurological evaluation & \multicolumn{4}{c}{ IPVH level } \\
\cline { 2 - 5 } & 1 & 11 & 111 & IV \\
\hline Normal & 14 & 10 & 2 & 0 \\
Abnormal & 2 & 2 & 3 & 5 \\
Suspicious & 5 & 3 & 3 & 1 \\
Total & 21 & 15 & 8 & 6 \\
\hline
\end{tabular}


Table 3. Frequency of abnormal neurological signs in newborns with andwithout IPVH.

\begin{tabular}{lcccc}
\hline & \multicolumn{2}{c}{ Without IPVH } & \multicolumn{2}{c}{ With IPVH } \\
Abnormal signs & Abnormal & Suspicious & Abnormal & Suspicious \\
\hline Trunk hypotonia and fallen head & 4 & - & 6 & - \\
Flexor tonus UE>LE* & 3 & 3 & 7 & 5 \\
Abnormal head control & 9 & 7 & 8 & 8 \\
Tremor and startles & 2 & 1 & 6 & 2 \\
Thumb adduction & 1 & - & 8 & 4 \\
Abnormal Moro reflex & - & - & 2 & 1 \\
Asymmetry & 2 & 1 & 8 & 3 \\
Abnormal eye movement & 1 & - & 5 & 1 \\
Poor orientation & 2 & 1 & 8 & 4 \\
Irritability & 3 & 4 & 4 & 4 \\
\hline
\end{tabular}

*UE > LE, upper extremities / lower extremities

Table 4.Relationship between the neurological evaluation of newborns with IPVH and the associated brain abnormalities

\begin{tabular}{lll}
\hline Normal & Abnormal & Suspicious \\
\hline $\mathrm{II}+\mathrm{VD}^{1}$ & $\mathrm{III}+\mathrm{PVL}^{2}$ & $\mathrm{II}+\mathrm{VD}$ \\
$\mathrm{III}+\mathrm{VD}+\mathrm{VPD}^{3}$ & $\mathrm{IV}+\mathrm{PC}^{4}$ & $\mathrm{III}+\mathrm{PC}+\mathrm{VD}$ \\
& $\mathrm{IV}+\mathrm{PVL}$ & $\mathrm{III}+\mathrm{PC}$ \\
& $\mathrm{I}+\mathrm{PVL}$ & \\
& $\mathrm{III}+\mathrm{PVL}+\mathrm{PC}$ & \\
& $\mathrm{IV}+\mathrm{PVL}+\mathrm{VD}+\mathrm{VPD}$ & \\
& $\mathrm{IV}+\mathrm{PC}+\mathrm{VD}+\mathrm{VPD}+$ \\
& $\mathrm{IV}+\mathrm{PVL}$ & \\
\hline
\end{tabular}

1 VD, Ventricular dilatation; 2 PVL, Periventricular leukomalacia; 3 VPD, Ventricular peritoneal derivation; 4 PC, Porencephalic cysts.

Table 5. Values of " $p$ ” derived from polytomic logistic regression.

\begin{tabular}{lc}
\hline Variable & $p$ \\
\hline 1. Degree of hemorrhage & 0.0057 \\
2. Gestational age & 0.0017 \\
3. Sex & 0.5236 \\
4. Apgar at $5^{\text {th }}$ minute & 0.0397 \\
5. Weight & 0.1242 \\
6. Assisted ventilation & 0.0344 \\
7. Neurological alterations & 0.0225 \\
8. Associated brain abnormalities & 0.0005 \\
\hline
\end{tabular}

Table 6. Factors associated with the neurological evaluation in a multiple analysis using the multivariate polytomic logistic regression.

\begin{tabular}{lc}
\hline Variable & $p$ \\
\hline Intercept & 0.6420 \\
Associated brain abnormalities & 0.0019 \\
Gestational age & 0.0051 \\
\hline
\end{tabular}


Table 7. Association between brain abnormalities and gestational age.

\begin{tabular}{cccc}
\hline $\begin{array}{c}\text { Associated abnormalities } \\
\text { Suspicious / abnormal }\end{array}$ & $\begin{array}{c}\text { Gestational } \\
\text { age (weeks) }\end{array}$ & $\begin{array}{c}\text { Probability \% } \\
\text { Normal/Abnormal }\end{array}$ \\
\hline No & $27-31$ & 72 & 60 \\
No & $32-35$ & 96 & 83 \\
Yes & $27-31$ & 8.9 & 21 \\
Yes & $32-35$ & 48.7 & 46 \\
\hline
\end{tabular}

A multivariate model was created from the univariate analysis for the polytomic logistic regression (Table 5). When the regression model was completed, associated brain abnormalities and gestational age remained as independent variables associated with the neurological evaluation (Table 6).

The probability to normality for a child aged 27 to 31 weeks with no associated brain abnormalities was $72 \%$, whereas for a child with the same gestational age in the presence of associated brain abnormalities the probality was $48.7 \%$ (Table 7 ).

\section{DISCUSSION}

Our study has shown that the neurological evaluation of neonates with IPVH was significantly influenced by the extent of hemorrhage There was no significant association with birth weight, Apgar score at the $5^{\text {th }}$ minute, and use of assisted ventilation. The presence of brain abnormalities was usually associated with neurological evaluation in the univariate analysis.

There was a significant association between the neurological evaluation and the level of IPVH in the univariate analysis. This association disappeared in the multiple analysis.A greater number of abnormal signs were found in the neonates with IPVH, including trunk hypotonia associated with a fallen head and abnormal head control, persistent thumb adduction, trembling, startle, asymmetry, and poor orientation.

Our findings agree with those related by Dubowitz et al. ${ }^{4}$, and Anderson et al. ${ }^{8}$, mainly trunk hypotonia and abnormal head control. A greater upper extremities flexor tonus involvement in relation to lower extremities is indicative of pyramidal tract involvement ${ }^{9,11}$. Otherwise, recognized tremor and startle in newborns look like to correlate with a higher risk of cerebral palsy ${ }^{12}$. In our study, permanent thumb adduction was related in $67 \%$ of newborns with IPVH, and this feature could be correlated with cortico-spinal tract lesion.

The neurological examination was abnormal or suspicious in the majority of the newborns with HPIV and associated brain abnormalites, while in newborns with age range between 27-29 gestational weeks the abnormal or suspicious neurological examination was found in $75 \%$ of the cases.

Since IPVH is characteristic of premature infants, particularly in those with gestational age less than 32 weeks, an improvement in neonatal intensive care is necessary in order to increase the survival rates for these infants ${ }^{1,2,13}$.

The precocious clinical diagnosis of IPVH depends on early recognition of the clinical aspects, usually obtained by an ultrasonic scan, which is more convenient and less hazardous than other procedures $^{1,13,14}$.

In conclusion, most neonates with IPVH showed a significant correlation between the clinical and laboratory findings with neurological evaluation. 


\section{REFERENCES}

1. Marba STM. Hemorragia periventricular-intraventricular: incidência em recém-nascidos vivos e sua associação com idade gestacional, peso, crescimento intra-uterino e óbito neonatal. Dissertação de Mestrado, Faculdade de Ciências Médicas da UNICAMP, Campinas 1993.

2. Papile LA. Periventricular-intraventricular hemorrhage.In Fanaroff A, Martin RJ. Neonatal-perinatal medicine: diseases of the fetus and infants. 5Ed. St. Louis: Mosby Year Book, 1992: 719-729.

3. Dubowitz LMS, Dubowitz V.The neurological assessment of the preterm and fullterm newborn. Clin Dev Med 1981;79:103-108.

4. Dubowitz LMS, Dubowitz V, Palmer PG, Millers G, Fawer CL, Levene MI. Correlation of neurologic assessment in the preterm newborn infant with outcome at 1 year.J Pediatr 1984;105:452-456.

5. Brazelton TB. Neonatal behavioral assessment scale.Clin Dev Med 1973;50:53-59.

6. Hosmer DW, Lemeshow S. Applied logistic regression. New York: John Wiley \& Sons, 1989.

7. Strokes ME, Davis CS, Koch GG. Categorial data analysis using the SAS system.North Carolina: SAS Institute, 1995.

8. AndersonL LT, Garcia-Coll C, Vohr BR,et al. Behavioral characteristics and early temperament of prematures infants with intracranial hemorrhage.Early Hum Dev 1989;18:273-283.

9. Amiel-Tison C. Does neurological assessment still have a place in the NICU? Acta Paediatr 1996;416(Suppl): 31-38.

10. Amiel-Tison C. Neurological evaluation of the maturity of newborn infants.Arch Dis Child 1968,43:89-93.

11 Dubowitz LMS, Dubowitz V, Goldberg C. Clinical assessment of gestational age in the newborn infant. J Pediatr 1970,77:1-5.

12. Nelson KB, Ellenberg JH. Neonatal signs as predictors of cerebral palsy. Pediatrics 1979;64:225-232.

13. Papile LA, Munsick-Bruno G, Schaefer A Relationship of cerebral intraventricular hemorrhage and early childhood neurologic handicaps.J Pediatr 1983;103:273-277.

14. Volpe JJ. Intracranial hemorrhage: periventricular-intraventricular hemorrhage of the premature infant. In Volpe JJ (ed). Neurology of the newborn. 2Ed. Philadelphia: Saunders, 1987: 311-361. 